\title{
Implementation of servant leadership in profit and non-profit context: is it different?
}

\author{
Diah Astrini Amir ${ }^{1}$, Claudius Budi Santoso², Rasistia Wisandianing Primadineska ${ }^{3}$ \\ ${ }^{1}$ Sekolah Tinggi IImu Manajemen YKPN, Yogyakarta, Indonesia \\ ${ }^{2}$ Department of Management, Faculty of Economics and Business, Universitas Gadjah Mada, Yogyakarta, Indonesia \\ ${ }^{3}$ Sekolah Tinggi IImu Manajemen YKPN, Yogyakarta, Indonesia
}

\begin{abstract}
The purpose of this study is to examine the differences between servant leadership (SL) in the profit and non-profit organization sectors. This study also examines the effectiveness of SL on the subordinate performance in profit and non-profit organizations. A total of 254 subordinates from profit and non-profit organizations participated in this study. This study used non-probability sampling, purposive sampling technique. This study uses MANOVA to examine the differences between SL in profit and non-profit organizations and uses simple regression to examine the effect of SL on employee performance. The results of the study report that there are no significant differences between servant leadership in profit or nonprofit organizations. Servant leadership also consistently has a positive and significant effect on subordinate Organizational Citizenship Behavior (OCB) for both profit and nonprofit organizations. This research was measured using perceptions of subordinates and using a quantitative approach. The early emergence of SL was associated with religious organizations (non-profit) so that SL was attached to leadership that was more appropriate in non-profit organizations. However, some argue that SL effective in the profit organization sector. This study is expected to provide empirical evidence regarding the application of servant leadership in profit vs non-profit organizations in servant leadership studies.
\end{abstract}

Keywords servant leadership; organizational citizenship behavior; profit organization; non-proft organization; social learning theory

\section{INTRODUCTION}

Servant leadership (SL) is leadership style that focuses on people (people oriented). SL became one of the most popular leadership studies after it was introduced by Greanleaf in 1970. The servant leadership (SL) study at the beginning of its emergence is mostly associated with non-profit organizations (Krekeler, 2010; Sendjaya \& Sarros, 2002). As the study developed, SL began to be investigated in profit organizations (business). However, the effectiveness of implementing SL in the profit and non-profit organization sector is still debated (Palumbo, 2016). Profit organizations are characterized by high task complexity and dynamic, while non-profit organizations tend to be routine tasks and static (Farrow et al., 1980). Researchers argue that SL is more appropriate in a static organizational context than a dynamic organizational context (Smith et al., 2004). On the other hand, there have been many studies of SL conducted in the context of profit organizations (Choudhary et al., 2013; Melchar \& Bosco,
2010). This show that $S L$ is also found to be effective in various organizational context, not only in non-profit organization. The inconsistency of the results of these previous studies makes it interesting to reveal the implementation of SL in non-profit compare to profit context (Eva et al., 2019; Han et al., 2010; van Dierendonck, 2011).

In addition to examining the differences between the application of $S L$ in the profit and non-profit organization sectors, it is also necessary to test the effectiveness of implementing SL on the behavior of subordinates. This is because one way to test the effectiveness of leadership is to test its effect on the behavior of subordinates. SL is a leadership style that has a natural calling to serve others (Greenleaf, 1977). Therefore, it is believed that the leader who serves will transmit the behavior to his subordinates. Specifically, subordinates will be motivated to serve others, in the context of the organization, then compelled to serve colleagues and also their organizations. Leadership behavior that serving others is believed to affect subordinate organizational 
citizenship behavior (van Dierendonck, 2011). In line with the urgency of testing the implementation of SL in the profit and nonprofit organizations, it is also interesting to examine the effect of implementing SL on the behavior of subordinates.

This research was conducted in Indonesia. Indonesia is one of the countries characterized by high power distance (House et al., 2004). In the study literature, SL develops in the context of western countries characterized by low power distance. Therefore, there is an urgency to enrich SL literature in different country contexts (Eva et al., 2019; van Dierendonck, 2011). The results of SL studies in different country contexts can enrich the results of studies in the SL field.

\section{LITERATURE REVIEW AND HYPOTHESES DEVELOPMENT}

\section{Servant leadership in non-profit organizations}

Greenleaf (1977) in his book Servant as Leader suggested that the initial idea of servant leadership originated from the illustrated story of Herman Hesse. The story is about the spiritual journey of a group of people that one of the members of the trip is a servant named Leo. Leo is in charge of arranging group trips. The group's trip went so well until one moment, Leo disappeared from the group's trip. The loss of Leo made the group confused and did not know the direction. From this illustration, Greenleaf concludes that the servant on the spiritual journey is truly the leader. Based on this initial idea, the researchers then attached SL to organizations that were spiritual/religious which were a type of non-profit organization (Flanike, 2006; Niewold, n.d.; Shirin, 2014; Winston, 2004).

The results of previous studies have reported that the application of SL is effective in the context of non-profit organizations, such as sports volunteer clubs, NGOs, religions, social movements, educational institutions (Allen et al., 2018; Flanike, 2006; Pekerti \& Sendjaya, 2010; Schneider \& George, 2011; Shirin, 2014; Wells \& Peachey, 2016). The results of research conducted at non-profit organizations in North America also revealed that $53.7 \%$ of non-profit organization leaders associate themselves with the concept of SL compared to other leadership styles such as transformational (34.8\%), charismatic (29.4\%), and transactional $(5.1 \%)$ (Sargeant \& Day, 2018). This revealed that SL has the same characteristics and motivations as the context of non-profit organizations (Keith, 2009). Despite this, SL still receives little attention as a potential leadership style in non-profit organizations (Palumbo, 2016).

\section{Servant leadership in profit organization}

The early development of SL studies was attached to religious organizations. The concept of SL focus on serving subordinates. The concept of SL in line with the thought of the holy bible/leadership of Jesus Christ which is focused on the service of the people. As leadership studies develop, researchers also began to conduct research related to the application of SL in profit organizations. Keith as CEO of the Greenleaf Center for Servant Leadership in 2009 in his speech offered the concept of ethical, practical, and meaningful leadership through the SL concept which is needed by business organizations today.

The results of previous studies also report that SL has a positive influence on subordinates in the context of business organizations (profit). SL has an impact on subordinates' involvement in the restaurant business (Carter \& Baghurst, 2013), SL is effective in the organization of automotive dealers (Melchar \& Bosco, 2010) and hospitality business (Topcu et al., 2015). On the other hand, the researchers also revealed that $S L$ is not appropriate to be applied in the profit organizations which demanded a dynamic environment. SL works better in static environments compared to dynamic environments (Smith et al., 2004). Meanwhile, the literature related to the application of SL in a dynamic environment is still very limited (Stone et al., 2004), and it is interesting to examine SL in the context of profit organizations (Schneider \& George, 2011).

Based on the argumentation and support of the literature, this research formulates the first hypothesis:

H1: There is no difference in the application of SL in profit organizations and non-profit organizations. However, the score of SL in non-profit 
organizations is higher than profit organizations.

\section{The effect of servant leadership on $O C B$ in non-profit and profit organizations}

Social learning theory (Bandura, 1977) holds that a person will tend to learn from his social environment. Specifically, leaders who become role models for their environment will become role models and their behavior tends to be adapted by their surroundings. Leaders who are characterized by serving leadership have high ethical behavior and a natural willingness to serve their subordinates. When referring to social learning theory, the behavior of SL leaders tends to have an impact on the similar behavior of their subordinates. (van Dierendonck, 2011) states that the behavior is a behavior of organizational citizenship, where someone will be motivated to help fellow (colleagues) and the organization as a whole. Based on previous studies, the effect of SL on subordinate OCB has been reported to be positive and significant (Dixon, 2013; GÜÇEL \& Begec, 2012; Mathur \& Negi, 2014). However, there is debate among researchers regarding the application of SL in the context of profit and non-profit organizations (as arguments built on hypothesis 1) so that it becomes relevant to examine the effects of SL application on the behavior of subordinates separately in the context of profit and non-profit organizations.

Based on the argumentation and support of the literature, this research formulates the second hypothesis, namely:

H2: SL has a significant positive effect on $O C B$, both profit and non-profit organizations.

\section{METHODS}

\section{Procedures and samples}

This study uses a quantitative approach. Data collection methods using online questionnaires. The number of respondents who participated was 254 respondents with the details of 127 respondents working on profit organizations and 127 respondents working on non-profit organizations in Indonesia. Total of $117(45,5 \%)$ respondents were female, $137(53,3 \%)$ were male, and over $96,9 \%$ had completed university degree. The sample size regulation refers to the rule of thumb which is 15:1 from the variable studied (Hair Jr et al., 2014). Thus, the sample size in this study has met the rule of thumb.

The sampling technique is nonprobability sampling, namely a purposive sampling technique where respondents are determined based on certain criteria (Cooper \& Schindler, 2014). The determination of the criteria for respondents is to have experience working with supervisor for at least one year at a profit or non-profit organization in Indonesia. Thus, respondents are expected to have had quite a long experience of interacting with their leaders.

\section{Measurement}

The SL variable is measured by 30 items developed by (Dierendonck \& Nuijten, 2011). OCB variables are measured by 16 items developed by (Lee \& Allen, 2002). All items examined were measured by a 5-point Likert scale, ranging from 1 (strongly disagree) to 5 (strongly agree).

\section{RESULTS AND DISCUSSION}

\section{Validity}

This study examines the construct validity using confirmatory factor analysis (CFA) with the varimax method. The specified factor loading value $>0.5$ (Hair Jr et al., 2014). The prerequisite before factor analysis is the fulfillment of Kaiser-MeyerOkin (KMO) value> 0.5 and Bartlett's Test is significant at $<0.05$ (Hair Jr et al., 2014).

The validity test results in this study were conducted in two rounds. In the first round, the KMO value was 0.917 with a significance of Bartlett's Test 0,000 . However, out of 30 SL variable items, 8 items did not meet the specified factor loading value. Also, from 16 OCB variable items, 2 items do not meet the specified loading factor. The ten items that did not meet the factor loading value requirements were eliminated in the second round. In the second round obtained a better KMO value of 0.933 with a significance of Bartlett's Test 0,000 . The results of the factor loading analysis in this second round showed that as many as 36 items (22 SL variable items and 14 OCB variable items) had fulfilled the factor loading value ie 
greater than 0.5 . These results indicate that the measurement items studied are valid (see Table 1).

Table 1.

Validity test result

\begin{tabular}{|c|c|c|}
\hline \multirow[t]{2}{*}{ Item } & \multicolumn{2}{|c|}{ Component } \\
\hline & 1 & 2 \\
\hline SL1 & 0,645 & \\
\hline SL2 & 0,698 & \\
\hline SL3 & 0,717 & \\
\hline SL4 & 0,724 & \\
\hline SL5 & 0,666 & \\
\hline SL6 & 0,515 & \\
\hline SL7 & 0,683 & \\
\hline SL8 & 0,623 & \\
\hline SL9 & 0,681 & \\
\hline SL11 & 0,644 & \\
\hline SL13 & 0,622 & \\
\hline SL16 & 0,527 & \\
\hline SL19 & 0,707 & \\
\hline SL20 & 0,663 & \\
\hline SL23 & 0,808 & \\
\hline SL24 & 0,781 & \\
\hline SL25 & 0,733 & \\
\hline SL26 & 0,812 & \\
\hline SL27 & 0,823 & \\
\hline SL28 & 0,698 & \\
\hline SL29 & 0,751 & \\
\hline SL30 & 0,660 & \\
\hline PKO2 & & 0,532 \\
\hline PKO4 & & 0,658 \\
\hline PKO5 & & 0,584 \\
\hline PKO6 & & 0,688 \\
\hline PKO7 & & 0,647 \\
\hline PKO8 & & 0,512 \\
\hline PKO9 & & 0,620 \\
\hline PK010 & & 0,664 \\
\hline PK011 & & 0,594 \\
\hline PK012 & & 0,569 \\
\hline PK013 & & 0,643 \\
\hline PK014 & & 0,602 \\
\hline PK015 & & 0,657 \\
\hline PK016 & & 0,674 \\
\hline
\end{tabular}

\section{Reliability}

This study tested reliability based on Cronbach's Alpha minimum value of 0.6 (Hair Jr et al., 2014). The results of the reliability test of 22 items of SL variables showed a Cronbach's Alpha value of 0.951 . Meanwhile, 14 OCB variable items showed
Table 2.

Reliability test result

\begin{tabular}{lll}
\hline Variable & Cronbach's Alpha & N of Items \\
\hline SL & 0,951 & 22 \\
PKO & 0,886 & 14 \\
\hline
\end{tabular}

a Cronbach's Alpha value of 0.886 . These results indicate that the measurement items studied are reliable (see Table 2).

\section{Descriptive results}

The results of descriptive and correlation tests. The results reported that the mean values of the two variables studied were $>3.00$. That means the average respondent has a high response to the variable SL (3.67) and OCB (3.93). In addition, the correlation test results showed that $S L$ had a significant correlation with OCB $(r=0.424 ; p<0.01)$ (see Table 3).

\section{Hypothesis testing results}

Hypothesis 1 states that there is no significant difference between $S L$ in the profit or non-profit organization sector. The results of the MANOVA to test the differences between SL in profit and nonprofit organizations (see Table 4). The results show that there is no difference between the SL aggregate value and the value of the seven SL dimensions in profit and non-profit organizations ( $p>0.05)$ while confirming that hypothesis 1 is supported. However, the comparison of mean SL values in non-profit organizations is largely higher than the mean SL values in profit organizations, except for the forgiveness SL dimension that reports otherwise.

Hypothesis 2 states that SL has a significant positive effect on OCB both profit and non-profit organizations. Table 5 confirms that the influence of SL on OCB is positive significant in non-profit organizations $(\beta=0.437 ; t=5.426 ; p$ $<0.001)$ and profit organizations $(\beta=0.399$; $t=4.872 ; p<0.001)$. Thus, it was concluded that hypothesis 2 was supported.

Table 3.

Descriptive and correlation statistic

\begin{tabular}{lcccc}
\hline Variable & Mean & SD & SL & OCB \\
\hline SL & 3,67 & 0,60 & 1 & $0,424^{\star *}$ \\
OCB & 3,93 & 0,45 & $0,424^{* *}$ & 1 \\
\hline
\end{tabular}


Table 4.

Univariate statistics of the servant leadership dimensions in profit and non-profit organization

\begin{tabular}{lccccc}
\hline Dependent & \multicolumn{2}{c}{ Non-Profit } & \multicolumn{2}{c}{ Profit } & \multirow{2}{*}{ F } \\
\cline { 2 - 5 } Variables & Mean & Std. Deviation & Mean & Std. Deviation & \\
\hline SL & 3,725 & 0,569 & 3,608 & 0,629 & 2,431 \\
EMP & 3,867 & 0,656 & 3,730 & 0,708 & 2,562 \\
SB & 3,429 & 0,912 & 3,220 & 0,981 & 3,080 \\
ACC & 4,028 & 0,582 & 3,965 & 0,643 & 0,670 \\
FRGV & 2,748 & 1,112 & 2,819 & 1,057 & 0,271 \\
AUT & 3,563 & 0,812 & 3,378 & 0,888 & 3,005 \\
HUM & 3,654 & 0,761 & 3,559 & 0,841 & 0,882 \\
STW & 3,945 & 0,746 & 3,843 & 0,785 & 1,134 \\
\hline
\end{tabular}

Table 5.

Regression results of the effect SL on OCB in profit and non-profit organization

\begin{tabular}{|c|c|c|c|c|c|}
\hline \multirow[b]{2}{*}{ Variable } & \multicolumn{2}{|l|}{ Non-Profit } & \multicolumn{3}{|c|}{ Profit } \\
\hline & $\begin{array}{l}\text { Standardized } \\
\text { Coefficient }(\beta)\end{array}$ & P-value & $\begin{array}{l}\text { Standardized } \\
\text { Coefficient }(\beta)\end{array}$ & T value & P-value \\
\hline \multirow[t]{4}{*}{ SL } & 0,437 & 0,000 & 0,399 & 4,872 & 0,000 \\
\hline & Adjusted $\mathrm{R}$ square $=0,184$ & & Adjusted R square &, 153 & \\
\hline & $F=29,436$ & & $F=23,737$ & & \\
\hline & Significant $=0,000$ & & Significant $=0,000$ & & \\
\hline
\end{tabular}

The study results show that $\mathrm{SL}$ is effective in both profit and non-profit organizations. However, the application of $\mathrm{SL}$ in the context of a non-profit organization is more effective when compared to a profit organization. This study supports the research results from Sargeant \& Day (2018) that SL values are in accordance with organizational values in the non-profit context.

The results of this study also enrich the findings of previous research that SL has an effect on subordinate OCB (Dixon, 2013; GÜÇEL \& Begec, 2012; Mathur \& Negi, 2014). But more specifically, this study enriches empirical studies related to the effect of SL on OCB in the context of profit and non-profit organizations in one study.

\section{CONCLUSION}

This research provides empirical evidence regarding the application of SL in the profit and non-profit sectors. The results of the study show that the implementation of $S L$ is universal, which is in accordance with the context of any organizations (profit and nonprofit) and effectively applied in Indonesia which characterized by high power distance. The results of the study also showed the effectiveness of the application of SL to subordinate organizational citizenship behavior both in the context of profit and non-profit organizations.

The results of this study have implications on both the academic and practitioner side. From the academic side, this research enriches the literature related to the application of SL in the profit and nonprofit sectors and enriches the SL literature in the context of non-western cultures characterized by high power distance. From the practitioner side, this research provides an alternative style of leadership that is in line with current conditions which sees the need to focus on the human aspect.

This research has several limitations that can be developed for further research. First, this research was measured using perceptions of subordinates. Future studies can use a variety of assessment sources, for example by using the perception of leaders and subordinates for comprehensive results. Second, this research uses a quantitative approach. Future studies can combine qualitative (descriptive) approaches to get more comprehensive results regarding the differences in the application of SL in the context of profit vs non-profit organizations. 


\section{REFERENCES}

Allen, S., Winston, B. E., Tatone, G. R., \& Crowson, H. M. (2018). Exploring a model of servant leadership, empowerment, and commitment in nonprofit organizations. Nonprofit Management and Leadership, 29(1), 123-140. https://doi.org/10.1002/nml.21311

Carter, D., \& Baghurst, T. (2013). The influence of servant leadership on restaurant employee engagement. Journal of Business Ethics, 124(3), 453-464. https://doi.org/10.1007/s10551-0131882-0

Choudhary, A. I., Akhtar, S. A., \& Zaheer, A. (2013). Impact of transformational and servant leadership on organizational performance: a comparative analysis. Journal of Business Ethics, 116(2), 433440. https://doi.org/10.1007/s 10551 012-1470-8

Cooper, D. R., \& Schindler, P. S. (2014). Business research methods (12nd ed.). McGraw-Hill.

Dierendonck, D. Van, \& Nuijten, I. (2011). The servant leadership survey: development and validation of a multidimensional measure. Journal of Business and Psychology, 26(3), 249-267. https://doi.org/10.1007/s10869-0109194-1

Dixon, D. L. (2013). Relationships among servant leadership, organizational citizenship behavior, and school climate in alabama high schools [The University of Alabama]. https://ir.ua.edu/handle/123456789/188 2

Eva, N., Robin, M., Sendjaya, S., van Dierendonck, D., \& Liden, R. C. (2019). Servant leadership: A systematic review and call for future research. Leadership Quarterly, 30(1), 111-132. https://doi.org/10.1016/j.leaqua.2018.07 .004

Farrow, D. L., Valenzi, E. R., Bass, B. M., \& Binghamton, Y. (1980). A comparison of leadership and situational characteristics within profit and nonprofit organizations. Academy of Management Proceedings, 1, 334-338. https://journals.aom.org/doi/abs/10.546 5/AMBPP.1980.4977898

Flanike, F. (2006). Is the bible relevant to servantleadership? Journal of Applied Christian Leadership, 1(1), 32-39. https://digitalcommons.andrews.edu/cgi /viewcontent.cgi article $=1002 \&$ context $=$ jacl

GÜÇEL, C., \& Begec, S. (2012). The Effect of the servant leadership on organizational citizenship behavior: Case study of a university. International Journal of Social Sciences and Humanity Studies, 4(1), 107-116.

Hair Jr, J. F., Black, W. C., Babin, B. J., \& Anderson, R. E. (2014). Multivariate data analysis (7th ed.). Pearson Education Limited.

Han, Y., Kakabadse, N. K., \& Kakabadse, A. (2010). Servant leadership in the people's republic of china: a case study of the public sector. Journal of Management Development, 29(3), 265281.

https://www.emerald.com/insight/conten t/doi/10.1108/02621711011025786/full/ html

House, R. J., Hanges, P. J., Javidan, M., Dorfman, P. W., \& Gupta, V. (2004). Culture, leadership, and organizations the GLOBE study of 62 societies. SAGE Publications.

Keith, K. M., \& Dinner, C. F. (2009). Servant Leadership in Business. University of Washington Seattle, Washington.

Krekeler, L. a. (2010). The Relationship Between Servant Leadership Behavior and Individual Personality Style in New York Annual Conference United Methodist Pastors. Theses, Paper 54.

Lee, K., \& Allen, N. J. (2002). Organizational citizenship behavior and workplace deviance: the role of affect and cognitions. Journal of Applied Psychology, 87(1), 131-142. https://doi.org/10.1037//0021 9010.87.1.131

Mathur, G., \& Negi, P. (2014). Servant leadership and organizational citizenship behaviour among employees of service sector. American International Journal of Research in Humanities, Arts and Social Sciences, 7(2), 191-196. https://www.researchgate.net/profile/Ga rima_Mathur3/publication/271198499_ Servant_Leadership_and_Organization al_Citizenship_Behaviour_Among_Emp loyees_of_Service_Sector/links/54c091 330cf21674ce9fcf94.pdf

Melchar, D., \& Bosco, S. (2010). Achieving high organization performance. The Journal of Business Inquiry, 9(1), 74-88.

Niewold, J. (n.d.). Beyond servant leadership. Journal of Biblical Perspectives in Leadership, 1(2), 118-134. 
https://www.regent.edu/acad/global/pub lications/jbpl/vol1 no2/JBPLVol1No2_Ni ewold.pdf

Palumbo, R. (2016). Challenging servant leadership in the nonprofit sector. Journal of Nonprofit Education and Leadership, $\quad 6(2)$, 81-98. https://doi.org/http://dx.doi.org/10.18666 /JNEL-2016-V6-12-6824

Pekerti, A. A., \& Sendjaya, S. (2010). Exploring servant leadership across cultures: Comparative study in Australia and Indonesia. International Journal of Human Resource Management, 21(5), 754-780. https://doi.org/10.1080/0958519100365 8920

Sargeant, A., \& Day, H. (2018). A study of nonprofit leadership in the US and its impending crisis. In Sustainable Philanthropy with Plymouth University. https://thenonprofitacademy.com/wpcontent/uploads/2018/11/WakeUpCall Report.pdf

Schneider, S. K., \& George, W. M. (2011). Servant leadership versus transformational leadership in voluntary service organizations. Leadership and Organization Development Journal, 32(1), 60-77. https://doi.org/10.1108/0143773111109 9283

Sendjaya, S., \& Sarros, J. C. (2002). Servant Leadership: Its Origin, Development, and Application in Organizations. Journal of Leadership \& Organizational Studies, $\quad$ 9(2), 57-64. https://doi.org/10.1177/1071791902009 00205

Shirin, A. (2014). Is servant leadership inherently christian? Journal of Religion and Business Ethics, 3(1), 13-25. https://via.library.depaul.edu/jrbe/vol3/is s1/13/

Smith, B. N., Montagno, R. V., \& Kuzmenko, T. N. (2004). Transformational and servant leadership: content and contextual comparisons. Journal of Leadership \& Organizational Studies, 10(4), 80-91. https://doi.org/10.1177/1071791904010 00406

Stone, A. G., Russell, R. F., \& Patterson, K. (2004). Transformational versus servant leadership : a difference in leader focus. The Leadership \& Organization Development Journal, 25(4), 349-361. https://doi.org/10.1108/0143773041053 8671
Topcu, M. K., Gursoy, A., \& Gurson, P. (2015). The role of the servant leadership on the relation between ethical climate perception and innovative work. European Research Studies Journal, 18(1), $\quad 67-80$. https://doi.org/10.35808/ersj/440

van Dierendonck, D. (2011). Servant leadership: A review and synthesis. Journal of Management, 37(4), 1228-1261. https://doi.org/10.1177/0149206310380 462

Wells, J. E., \& Peachey, J. W. (2016). Called to serve: exploring servant leadership in the context of sport-for-development. Journal of Sport for Development, 4(7), 12-24. https://jsfd.org/2016/12/03/called-toserve-exploring-servant-leadership-inthe-context-of-sport-for-development/

Winston, B. E. (2004). Servant leadership at heritage bible college: a single-case study. The Leadership \& Organization Development Journal, 25(7), 600-617. https://doi.org/10.1108/0143773041056 1486 